Cooper, N. W., D. N. Ewert, K. R. Hall, S. M. Rockwell, D. Currie, J. M. Wunderle, Jr., J. D. White, and P. P. Marra. 2018. Resighting data reveal weak connectivity from wintering to breeding grounds in a range-restricted and endangered long-distance migratory passerine. Avian Conservation and Ecology 13(1):9. https://doi.org/10.5751/ACE-01159-130109

Copyright (C) 2018 by the author(s). Published here under license by the Resilience Alliance.

Research Paper

\title{
Resighting data reveal weak connectivity from wintering to breeding grounds in a range-restricted and endangered long-distance migratory passerine
}

\author{
Nathan W. Cooper ${ }^{1}$, David N. Ewert ${ }^{2}$, Kimberly R. Hall ${ }^{2}$, Sarah M. Rockwell ${ }^{3}$, Dave Currie ${ }^{4}$, Joseph M. Wunderle, Jr. ${ }^{5}$, Jennifer D. \\ White ${ }^{6}$ and Peter P. Marra ${ }^{1}$ \\ ${ }^{1}$ Smithsonian Migratory Bird Center, ${ }^{2}$ The Nature Conservancy, ${ }^{3}$ Klamath Bird Observatory, ${ }^{4}$ Puerto Rican Conservation \\ Foundation, ${ }^{5}$ International Institute of Tropical Forestry, USDA Forest Service, ${ }^{6}$ U.S. Fish and Wildlife Service
}

\begin{abstract}
Understanding migratory connectivity is fundamental to the ecology, evolution, and conservation of migratory species. The endangered Kirtland's Warbler (Setophaga kirtlandii) has a restricted breeding range in early successional jack pine (Pinus banksiana) forests with most of the population in northern Michigan and smaller subpopulations in Wisconsin and Ontario. Kirtland's Warblers spend the winter almost exclusively in the Bahamian Archipelago. Using a combination of visual searches and radiotelemetry, we relocated 89 Kirtland's Warblers on the breeding grounds that were captured and banded on two islands in the central Bahamas. We quantified the strength of migratory connectivity using a new metric "MC," and the Mantel test. We found that regardless of wintering island, Kirtland's Warblers intermixed heavily on the breeding grounds, having migrated to sites throughout the entire breeding range. Our estimates indicated weak connectivity between the wintering and breeding grounds, as might be predicted from a species that uses ephemeral, early successional habitat on both the wintering and breeding grounds. These results suggest that loss of habitat at a wintering site would have a diffuse effect across the entire population. The importance of a landscape approach to conservation of this species, long recognized in the breeding season and more recently emphasized on the wintering grounds, is supported by our findings.
\end{abstract}

\section{Les données de réobservation révèlent une faible connectivité entre les aires d'hivernage et celles de reproduction d'un passereau migrateur de longue distance, en voie de disparition et de répartition restreinte}

RÉSUMÉ. La compréhension de la connectivité des déplacements migratoires est fondamentale pour l'écologie, l'évolution et la conservation des espèces migratrices. La Paruline de Kirtland (Setophaga kirtlandii), en voie de disparition, a une aire de reproduction restreinte aux forêts de pins gris (Pinus banksiana) de début de succession, et le gros de sa population se trouve dans le nord du Michigan, avec de petites sous-populations fréquentant le Wisconsin et l'Ontario. Cette paruline passe presque exclusivement l'hiver dans l'archipel des Bahamas. À l'aide de recherches visuelles et de la radiotélémétrie, nous avons relocalisé sur les aires de nidification 89 Parulines de Kirtland qui avaient été capturées et baguées sur deux îles dans le centre des Bahamas. Nous avons quantifié le degré de connectivité des déplacements migratoires au moyen d'une nouvelle mesure dite « MC » et du test de Mantel. Nous avons trouvé que, peu importe leur île d'hivernage, les Parulines de Kirtland migrent aux quatre coins de l'aire de reproduction et se mélangent grandement sur les sites de nidification. Nos estimations ont indiqué une faible connectivité entre les aires d'hivernage et celles de nidification, comme on peut le supposer chez une espèce qui fréquente des milieux éphémères de début de succession, tant sur les aires d'hivernage que de nidification. Nos résultats montrent que la perte d'habitat sur un site d'hivernage aurait un effet diffus dans la population entière. L'importance de l'approche de conservation par paysage pour cette espèce, privilégiée depuis longtemps en saison de reproduction et plus récemment prise en considération sur les aires d'hivernage, est corroborée par nos résultats.

Key Words: avian conservation; Bahamas; breeding grounds; endangered species; Kirtland's Warbler; migratory connectivity; Setophaga kirtlandii; wintering grounds

\section{INTRODUCTION}

The importance of understanding the full annual cycle of migratory species has become increasingly recognized over the past several decades (Marra et al. 2015). Migratory connectivity, the geographic and temporal linkages between two or more portions of the annual cycle, i.e., breeding, wintering, or migration (Webster et al. 2002, Bauer et al. 2016, Cohen et al. 2017), is a key component in understanding a species' full annual cycle. It has fundamental implications for ecology, evolution, and conservation because the strength of migratory connectivity defines the extent to which populations face the same or different selective pressures throughout the annual cycle (Webster and Marra 2005, Taylor and Norris 2010, Cohen et al. 2017). For example, when individuals that winter close together also breed close together, i.e., strong migratory connectivity, they will

Address of Correspondent: Nathan W Cooper, Migratory Bird Center, National Zoological Park, 3001 Connecticut Ave. NW, Washington, DC 20008, USA, nathanwands@gmail.com 
experience many of the same ecological forces. Without this understanding, population ecologists cannot determine how factors that limit local breeding or wintering populations will scale up to shape range-wide population dynamics (Rushing et al. 2016a). Moreover, we now know that conditions during any one part of the annual cycle can affect individuals in subsequent periods (Marra et al. 1998, 2015, Harrison et al. 2011, Rockwell et al. 2012, Cooper et al. 2015). The strength of migratory connectivity determines how these individual level carryover effects will impact populations. With the growing appreciation of full annual cycle ecology, migratory connectivity has become an important demographic parameter, and describing and quantifying it is a critical step in developing effective conservation plans (Rushing et al. 2016a).

Researchers have used a wide array of techniques to investigate migratory connectivity across a diverse suite of species. Morphological differentiation, stable isotopes, parasite species assemblages, and genetic markers are among the techniques that may resolve connectivity at broad spatial scales (Hobson 2005, Ricklefs et al. 2005, Smith et al. 2005, Boulet and Norris 2006, Rushing et al. 2014). In contrast, returns from banded birds (Marra et al. 2014), sightings of individuals during different parts of the life cycle (Gratto-Trevor et al. 2012), and tracking by radiotelemetry, satellite transmitters, and geolocators provide finer scale spatial resolution (Bridge et al. 2011, 2013). In particular, data obtained from both light-level and GPS geolocators have dramatically increased our ability to establish connectivity patterns for small organisms such as passerines (e.g., Stutchbury et al. 2009, Bächler et al. 2010, Heckscher et al. 2011, Ryder et al. 2011, Hallworth et al. 2015, Fraser et al. 2017). Each of these approaches, alone or integrated with others (Royle and Rubenstein 2004, Ruegg et al. 2014, Rushing et al. 2014, Hobson and Kardynal 2016), contributes to delimiting the distribution of populations throughout the annual cycle and thus provides a better understanding of migratory connectivity and its consequences for populations (Webster and Marra 2005, Wilcove and Wikelski 2008, Marra et al. 2015, Taylor and Stutchbury 2016).

Despite technological advances, the most precise method available to describe breeding and wintering connectivity is by visually locating the same individual from one season to the next. This has been done with some nonpasserines such as Brant Geese (Branta bernicla; Sedinger et al. 2007) and Piping Plovers (Charadrius melodus; Gratto-Trevor et al. 2012). Although there are records of individual passerines being found on both the breeding and wintering grounds (Sykes and Clench 1998, Rimmer and McFarland 2001, Koronkiewicz and Sogge 2002, Koronkiewicz et al. 2006, Townsend and Rimmer 2006, Ryder et al. 2011, Ewert et al. 2012), resighting probability is typically low, and therefore the number of records for any one species is often too low to permit description of migratory connectivity (Cohen et al. 2014, Thorup et al. 2014).

Even when sample sizes are large enough to permit analysis, spatial variation in resighting probability resulting from differences in both sampling effort and detection probability can introduce bias into estimates of migratory connectivity (Cohen et al. 2014, Thorup et al. 2014). Because banding and resighting data are typically collected opportunistically as part of many unrelated studies and then combined into large databases, e.g., the North
American Bird Banding Laboratory and EURING, most suitable habitat is not sampled at all, let alone in proportion to the abundance of individuals at those sites, leading to uneven sampling effort. Moreover, detection probability typically varies across the different habitat types and locations that are sampled (Cohen et al. 2014, Thorup et al. 2014). Accounting for imperfect detection and variation in detectability has become standard practice when estimating many different parameters, e.g., survival, abundance, density, and species diversity, that are fundamental to the understanding of animal ecology (Kellner and Swihart 2014), but few studies of migratory connectivity have addressed detectability (Cohen et al. 2014). Two recent studies discussed the difficulties of using resighting data to estimate migratory connectivity at continental or larger scales, especially for those species with few resightings (Cohen et al. 2014, Thorup et al. 2014). In contrast, species with restricted ranges and whose complete distribution is well known and accessible, such as the Kirtland's Warbler (Setophaga kirtlandii), present a unique opportunity to more readily use resighting data to describe and quantify migratory connectivity.

The Kirtland's Warbler is one of North America's rarest migratory passerines, breeding in young jack pine (Pinus banksiana) forest primarily in northern Michigan (Bocetti et al. 2014), with more recently established and much smaller subpopulations in Wisconsin (Trick et al. 2008) and Ontario (Richard 2008, 2013). Kirtland's Warblers winter almost exclusively in the Bahamian Archipelago (Bocetti et al. 2014, Cooper et al. 2017) and are one of the most range-restricted species in North America. Given that there are broadscale ecological forces, e.g., climate change, disease, and pest outbreaks, that could impact their entire breeding or wintering range, having a restricted range does have important ecological and conservation implications. However, finer scale ecological forces, e.g., hurricanes, fire, land-use changes, and habitat loss, might only impact individual islands or portions of islands within their wintering range. Thus, migratory connectivity is an important concept even for species with restricted ranges.

Our goal is to describe and quantify the migratory connectivity of Kirtland's Warblers. We combine resighting data from two sources: (1) birds banded on the wintering grounds and resighted during surveys on the breeding grounds, and (2) birds banded and radio-tagged on the wintering grounds and resighted following radiotelemetry on the breeding grounds. We use these data to describe how Kirtland's Warblers from two islands in the central Bahamas, where the species appears to be most abundant (Cooper et al. 2017; Cooper, Ewert, and Wunderle, personal observations), are distributed on the breeding range to determine the strength of connectivity between wintering and breeding areas. Migratory connectivity has only been described for more widely distributed species, and therefore, Kirtland's Warblers represent a unique data point along the continuum of range sizes. Furthermore, because of their restricted range size, this study represents the first connectivity study to sample this extensively across the breeding range. By describing and quantifying the migratory connectivity of this endangered species, we can begin to evaluate the potential impact of changes to winter habitat on breeding season population dynamics, information needed to implement full annual cycle conservation activities. 


\section{METHODS}

Nearly the entire world's population of Kirtland's Warblers breeds on approximately 89,000 ha of jack pine forest in the Upper and Lower Peninsulas of Michigan that is managed by the Michigan Department of Natural Resources, the U.S. Forest Service (USFS), and the U.S. Fish and Wildlife Service. During our study, a few Kirtland's Warblers also bred in Wisconsin (0-23 males) and Ontario (0-3 males). To assess migratory connectivity in Kirtland's Warblers, we used data from a color-banding and resighting effort (2002-2010) and a coded radio-tag telemetry study (2017). Birds for the banding and resighting study were captured and banded during the wintering period on Eleuthera, in the central Bahamas, and later searched for extensively on the breeding grounds. For the radiotelemetry study, we captured birds on Cat Island, which is also in the central Bahamas. We then used an array of automated telemetry towers, in addition to handheld and car-mounted radio antennas, to relocate and then resight tagged individuals on the breeding grounds.

\section{Banding and resighting study}

Kirtland's Warblers on Eleuthera, The Bahamas, were captured and banded by both focal and passive mist netting from 2002 to 2009 as summarized in Wunderle et al. $(2010,2014)$. We uniquely color banded 220 individuals (141 males, 79 females) on Eleuthera. Resighting data came from a variety of sources including the annual Kirtland's Warbler census and research projects carried out by S. M. Rockwell (e.g., Rockwell et al. 2012, 2017), but most detections $(75 \%)$ came as a result of our own systematic searches. In the Lower Peninsula, which held the vast majority of breeding Kirtland's Warblers (97\%-100\% depending on the year), we spent more than $\sim 1700$ hours from 2004 to 2009 systematically searching for banded individuals at a subset of sites within each breeding region (see Statistical analysis for region definitions). During our surveys, banded birds were located by walking transects at each site, except at sites with few birds where it was more efficient to check all males for bands by walking from one singing male to another. Transects were spaced in an attempt to locate all singing males at each site. We surveyed from sunrise to early afternoon, in May, June, and/or early July. At each site, we attempted to find all singing males and assess their banding status. In all years, we also incorporated observations of banded birds sighted opportunistically during other research projects. For all areas outside of the Lower Peninsula, which held very few birds $(<1 \%-3 \%)$, we relied on the annual census conducted by the Michigan and Wisconsin Departments of Natural Resources and the USFS that attempted to count all singing males in the population. This census was conducted across all known breeding habitat in the Lower and Upper Peninsulas (2003-2010) and began in Wisconsin in 2008 and in Ontario in 2004. During annual censuses in Wisconsin, Ontario, and the Upper Peninsula, each bird was checked for color bands, but for the Lower Peninsula, singing males were simply counted, and color bands noticed only opportunistically. For each resighted bird, we recorded the location using either a Trimble $(\sim 5 \mathrm{~m})$ or Garmin $(\sim 15 \mathrm{~m})$ GPS unit. For individuals that were resighted in multiple years, we only used the first resighting in the analyses. Because females were less detectable than males and encountered only opportunistically, we carried out all analyses with and without females.

\section{Radiotelemetry study}

During March and April 2017, we captured 63 Kirtland's Warblers (58 males, 5 females) across Cat Island, The Bahamas, using focal mist netting. We color banded individuals and attached a $0.35-\mathrm{g}$ coded radio tag (model $=$ NTQBW-2, Lotek Wireless Inc.) using a modified leg-loop harness (Rappole and Tipton 1991). Cooper et al. (2017) attached slightly larger (0.5 g) geolocators to Kirtland's Warblers and found no significant effects on migration timing, behavior, or return rate. We used an array of 11 automated telemetry towers (maximum range $=\sim 20$ $\mathrm{km}$; Taylor et al. 2017) located across the breeding grounds in the Lower Peninsula of Michigan to assist us in relocating individuals. These towers were located near $\sim 95 \%$ of all breeding territories in the Lower Peninsula. Once detected by an automated tower, we then used handheld telemetry to relocate and resight individuals. We only included individuals in the analysis that were detected via radiotelemetry (tower or handheld), resighted, and confirmed to be territorial. The few breeding areas in the Lower Peninsula that were not covered by the towers, all breeding areas in the Upper Peninsula, and all breeding areas in Ontario were searched using either car-mounted or handheld antennas. All individuals breeding in Wisconsin were checked for color bands as part of their annual census. Locations for all tagged individuals were recorded using a Garmin GPS unit ( $15 \mathrm{~m})$.

\section{Statistical analysis}

To determine if the proportion of birds migrating from Cat Island and Eleuthera correlated with the overall proportion of the Kirtland's Warbler population located within each of the 11 breeding regions, we first estimated population size within each breeding region using data from the annual Kirtland's Warbler census. For Eleuthera banded birds, we averaged population estimates from 2003 to 2010 and for Cat Island banded birds we only used the population estimate from 2017. We then tested for correlations between the proportion of individuals from Cat Island and Eleuthera that migrated to each breeding region and the proportion of the population breeding in that region using Pearson's correlation coefficient.

We estimated migratory connectivity using a metric (MC) recently developed by Cohen et al. (2017). The MC metric has a number of advantages over previous metrics, including its ability to both account for differences in relative abundance across the range and incorporate the location uncertainty that results from some types of tracking devices, e.g., light-level geolocators. To calculate this metric, one must define: (1) at least two breeding and two wintering regions, (2) the distances between the breeding regions and the distances between the wintering regions, (3) transition probabilities from each wintering region to each breeding region, (4) the relative abundance within each of the wintering regions, and (5) the sample size. We defined Eleuthera and Cat Island as separate wintering regions because we know that wintering individuals may move at fairly large scales within an island, e.g., at least $14.8 \mathrm{~km}$ (Wunderle et al. 2014), but we have no evidence of interisland movements within or between years. We evaluated migratory connectivity at two spatial scales: across the entire breeding range and only within the Lower Peninsula of Michigan, where $97 \%-100 \%$ of Kirtland's Warblers bred depending on the year. We first split the entire breeding range into 11 regions, with Wisconsin, Ontario, the Upper Peninsula each being its own 
Fig. 1. Wintering ground capture locations of male and female Kirtland's Warblers (Setophaga kirtlandii) banded on Eleuthera and Cat Island, The Bahamas, and their breeding ground resighting locations, connected by black and red lines, respectively. Ovals indicate the 11 breeding regions, which include all known breeding habitat. Insets show Wisconsin and the Upper Peninsula of Michigan (upper left), Ontario (upper right), and the Lower Peninsula of Michigan (labeled A-H, bottom). Thickness of lines and proportion of each breeding region filled by black (Eleuthera banded birds) and red (Cat Island banded birds) indicate the percentage of birds from these islands that migrated to each breeding region. See Table 1 for the percentage of the total Kirtland's Warbler population found within each region.

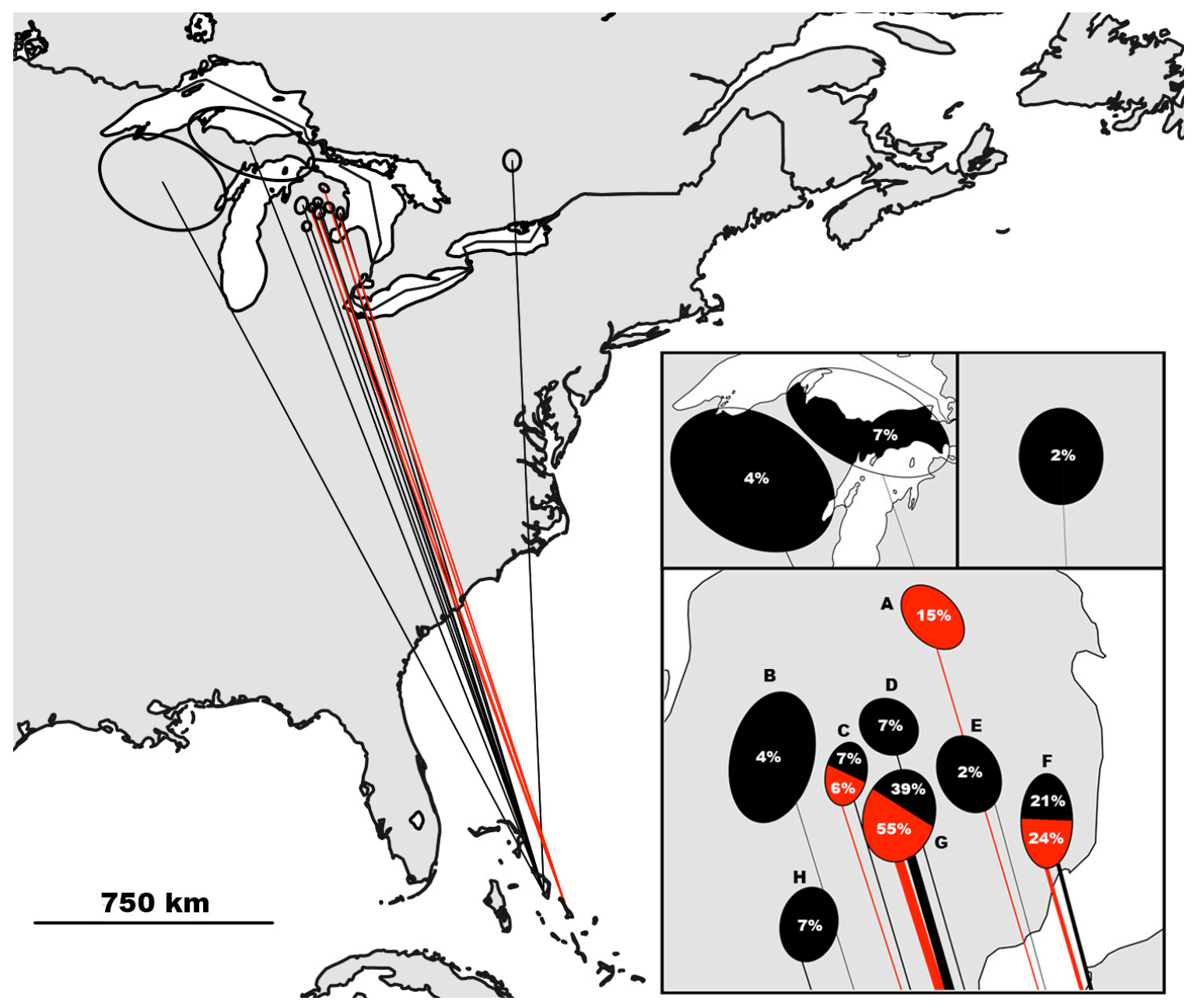

region, and the Lower Peninsula populations divided into 8 geographically distinct regions separated by unsuitable habitat (Fig. 1). Together, these 11 regions encompass all known Kirtland's Warbler breeding locations. The combination of very low abundance outside of the Lower Peninsula and the large distances between these peripheral breeding areas had the potential to conceal any signal of migratory connectivity within the core population. Therefore, we also estimated migratory connectivity in a separate analysis of birds found within the 8 breeding regions of the Lower Peninsula. To investigate whether the number of breeding regions influenced the MC metric, we also estimated MC, with and without including birds outside of the Lower Peninsula, after dividing the breeding range into fewer $(n=8)$ and more $(n=15,17)$ breeding regions. Distances between the regions were calculated as the great-circle distance between the centroids of each region. Using our resighting and telemetry data, we then calculated transition probabilities, i.e., the proportion of birds from Cat Island and Eleuthera that migrated to each breeding region. Our unpublished survey data (Cooper, Ewert, and Wunderle, unpublished data) from Eleuthera and Cat Island suggest no differences in relative abundance between the two wintering regions we defined. With these input values, we used the MigConnectivity (Hostetler et al. 2016) package in " $R$ " ( $\mathrm{R}$ Core Team 2017) to calculate the MC metric. An MC value of 0 indicates no relationship between the breeding and wintering season distances, i.e., weak connectivity, and an MC value of 1 indicates that the relative distances between individuals during the winter are the same as the distances between individuals during the breeding season, i.e., strong connectivity. Negative values of MC signify that individuals wintering close together are further apart during the breeding season. 
Table 1. Percentage of Kirtland's Warblers (Setophaga kirtlandii) from Cat Island and Eleuthera, The Bahamas, that migrated to each of 11 breeding regions located in the Lower Peninsula of Michigan (A-H), the Upper Peninsula of Michigan (UP), Wisconsin (WI), and Ontario $(\mathrm{ON})$ and how they compare to the percentage of the total population breeding in each region, as estimated by the annual Kirtland's Warbler census. Two population estimates are presented (2003-2010 and 2017) because Eleuthera birds were resighted from 2003 to 2010 and Cat Island birds were banded and resighted in 2017. See Figure 1 for locations of the 11 breeding regions.

\begin{tabular}{|c|c|c|c|c|c|c|c|c|c|c|c|}
\hline & \multicolumn{11}{|c|}{ Breeding Region } \\
\hline & A & $\mathrm{B}$ & $\mathrm{C}$ & $\mathrm{D}$ & $\mathrm{E}$ & $\mathrm{F}$ & $\mathrm{G}$ & $\mathrm{H}$ & WI & $\mathrm{ON}$ & UP \\
\hline $\begin{array}{l}\text { Population } \\
(2003-2010)\end{array}$ & $1.1 \%$ & $3.0 \%$ & $10.0 \%$ & $9.4 \%$ & $6.2 \%$ & $20.0 \%$ & $40.3 \%$ & $7.9 \%$ & $0.4 \%$ & $0.1 \%$ & $1.5 \%$ \\
\hline Eleuthera & $0 \%$ & $3.6 \%$ & $7.1 \%$ & $7.1 \%$ & $1.8 \%$ & $21.4 \%$ & $39.2 \%$ & $7.1 \%$ & $3.6 \%$ & $1.8 \%$ & $7.1 \%$ \\
\hline $\begin{array}{l}\text { Population } \\
\text { (2017) }\end{array}$ & $5.0 \%$ & $6.2 \%$ & $9.2 \%$ & $5.5 \%$ & $7.0 \%$ & $24.5 \%$ & $37.2 \%$ & $3.0 \%$ & $0.8 \%$ & $0.1 \%$ & $1.6 \%$ \\
\hline Cat Island & $15.1 \%$ & $0 \%$ & $6.1 \%$ & $0 \%$ & $0 \%$ & $24.2 \%$ & $54.5 \%$ & $0 \%$ & $0 \%$ & $0 \%$ & $0 \%$ \\
\hline
\end{tabular}

For sake of comparison with past studies, we also quantified the strength of migratory connectivity using a Mantel test (Ambrosini et al. 2009). The Mantel test evaluates the null hypothesis that wintering individuals were randomly mixed on the breeding grounds by testing for a correlation between a matrix of distances between wintering locations and a matrix of distances between breeding locations. We created matrices of great-circle distances between all pairwise combinations of resighted Kirtland's Warblers, separately for the wintering and breeding areas. The Mantel test on distance matrices was carried out in $\mathrm{R}$ (R Core Team 2017) using package "ade4" (Dray and Dufour 2007).

\section{RESULTS}

Of the 141 males and 79 females banded on Eleuthera, we resighted $43(30.5 \%)$ and $13(16.4 \%)$, respectively. Of the 56 Eleuthera banded birds resighted, $49(87.5 \%)$ were found in the Lower Peninsula, 4 (7.1\%) were found in the Upper Peninsula, 2 $(3.6 \%)$ were found in Wisconsin, and $1(1.8 \%)$ was found in Ontario. Of the 63 birds tagged on Cat Island, 33 (52\%) males were resighted, and all were found in the Lower Peninsula. The proportion of birds that migrated from Cat Island and Eleuthera to each breeding region strongly correlated with the proportion of the overall population of birds breeding within those regions (Cat Island: $r=0.94, P \leq 0.001$; Eleuthera: $r=0.97, P \leq 0.001$; Table 1). We observed that regardless of wintering origin, individuals showed a high degree of population mixing on the breeding grounds (Fig. 1).

Our estimate of migratory connectivity using the MC metric was near zero regardless of whether we included birds from the entire breeding range $(\mathrm{MC}=0.012)$ or limited our sample to the Lower Peninsula $(\mathrm{MC}=0.010)$. When we removed females from the analysis, $\mathrm{MC}$ estimates remained near zero (full breeding range $\mathrm{MC}=0.015$, Lower Peninsula $\mathrm{MC}=0.016$ ). Dividing the breeding region into fewer or more regions had no meaningful effect on our MC estimates $(\mathrm{MC}=0.009-0.017)$.

The Mantel test revealed a weak and nonsignificant correlation between wintering and breeding season distances when all birds were included $\left(r_{M}=-0.072, \mathrm{n}=89, P=0.97\right)$ and when only Lower Peninsula birds were included $\left(r_{M}=-0.028, \mathrm{n}=82, P=\right.$ 0.77). Similar to the MC metric, when we removed females from the analysis, the Mantel test still indicated a weak and nonsignificant correlation when all males were in the sample $\left(r_{M}\right.$ $=-0.049, \mathrm{n}=76, P=0.94)$ and when only Lower Peninsula males were included $\left(r_{M}=-0.019, \mathrm{n}=70, P=0.69\right)$.

\section{DISCUSSION}

Kirtland's Warblers wintering on two islands in The Bahamas intermixed heavily, establishing territories across the entire breeding range: from the northern (Michigan's Upper Peninsula) to the southern (northern portion of Michigan's Lower Peninsula), western (Wisconsin), and eastern (eastern Ontario) range limits. Correspondingly, all of our estimates indicated weak migratory connectivity. Although individuals from Cat Island migrated to only a subset of the breeding regions compared to individuals from Eleuthera (Fig. 1), the proportion of birds migrating from Cat Island and Eleuthera to each breeding region was strongly correlated with the proportion of the total population in each breeding region. Therefore, we believe that the more limited breeding distribution of Cat Island birds is likely attributable to chance rather than any real difference in migratory connectivity between the two islands. Our estimates of MC were largely unaffected by how we divided up the breeding range into regions. Given the patchiness of Kirtland's Warbler breeding habitat, defining regions was fairly intuitive. For more continuously distributed species, we recommend using rangewide demographic data to define natural populations following Rushing et al. (2016b).

There are comparatively few data regarding how breeding Kirtland's Warblers are distributed on the wintering grounds with which to compare our data. However, Cooper et al. (2017) recently recovered 27 light-level geolocators from male Kirtland's Warblers breeding across the entire Lower Peninsula. These data are coarse in resolution, given the inherent error associated with light-level geolocation (Lisovski et al. 2012), but they found that the 27 males wintered at sites located across the entire Bahamian Archipelago, with 1 male likely wintering in Cuba. Given these findings, it seems likely that the Kirtland's Warblers have weak migratory connectivity regardless of breeding or wintering location.

Using banding and resighting data to estimate migratory connectivity can be problematic because of biases associated with 
variation in resighting probability. Differences in detectability is one factor that can lead to variation in resighting probability. Our methods did not allow us to measure detectability, and therefore, we could not incorporate it into our estimates of migratory connectivity. However, we argue that Kirtland's Warbler detectability should be fairly similar among habitats and across our sampling periods. Kirtland's Warblers breed almost exclusively in jack pine forest, with more than $80 \%$ of their breeding range consisting of structurally homogenous plantations. Moreover, they are the most abundant bird species in these habitats, and from sunrise until early afternoon, males regularly sing loud, easily identifiable songs from arrival on the breeding grounds in early May until the postfledging period in July. In contrast to males, females are less detectable, but we found that analysis with and without females did not affect our estimates of migratory connectivity. Although we argue that detectability should be similar among breeding regions, resighting probability was higher using radiotelemetry $(52 \%)$ than with our visual searches (30.5\%). However, Cohen et al. (2017) recently simulated the effect of a fivefold difference in resighting probability between sampling regions and found that the effects on their migratory connectivity metric were negligible.

Variation in resighting probability can also result from incomplete and uneven sampling, i.e., survey effort not proportional to abundance. We relied primarily on systematic searches, which resulted in increased resighting rates $(30.5 \%$ of males, $16.4 \%$ of females) compared with large-scale banding and resighting studies (often $<1 \%$ ). Moreover, we sampled across the entire breeding range, and in each year, we found strong, positive correlations between the percentage of time spent conducting systematic searches and the percentage of the total population located within each user-defined breeding region $(r=0.77-0.97$, all $P \leq 0.026$ ), indicating that our sampling effort was proportional to population abundance. Several breeding regions in the Lower Peninsula were not sampled by the systematic searches in all years, but these areas generally contained a small percentage of the total population and were sampled for singing males as part of the annual census that the Michigan and Wisconsin Departments of Natural Resources and USFS conduct in an attempt to count all singing males in the population. Given our high resighting rate, and our relatively complete and even sampling design, we argue that our estimates of migratory connectivity using the MC metric are unlikely to be strongly affected by biases typically associated with banding and resighting data. Nonetheless, our sampling design is not feasible for most species, and thus future migratory connectivity studies should account for potential differences in resighting probability whenever possible (Cohen et al. 2014, Thorup et al. 2014).

\section{Drivers of weak connectivity}

The weak migratory connectivity found in Kirtland's Warblers might result, at least in part, from the ephemeral nature of their breeding and wintering habitat. Omitting all but the most extreme habitat generalists, most species track habitats as they change over time, but at varying temporal scales depending on the degree of specialization and the rate of habitat succession. Kirtland's Warblers are an extreme habitat specialist, breeding almost exclusively in jack pine forests, with just a few individuals breeding in red pine (Pinus resinosa). Moreover, jack pine forests are only suitable for a maximum of 15-20 years and are optimal for breeding for a shorter time period. Although site fidelity between years is generally high (Walkinshaw 1983), adult Kirtland's Warblers have dispersed up to $400 \mathrm{~km}$ between years (Walkinshaw 1983, Probst 1986; Ewert and Cooper, personal observations). Nestlings banded in Michigan's Lower Peninsula have dispersed to Wisconsin and Ontario, up to $676 \mathrm{~km}$ from their natal site (Walkinshaw 1983). On the wintering range, Kirtland's Warblers occupy early successional habitat (3-28 years postdisturbance; Wunderle et al. 2010), and birds can move at least $14.8 \mathrm{~km}$ within a winter, typically from resource-poor to resource-rich sites, because of a shifting mosaic of resource availability (Wunderle et al. 2014). Consequently, Kirtland's Warblers appear to be adapted to disperse to locate suitable habitat that is spatially and temporally patchy across the landscape during both breeding and wintering seasons (Probst 1986, Wunderle et al. 2010). This increased propensity to disperse is important because recent simulations have shown that even low levels of long-distance dispersal can weaken migratory connectivity over time (Cohen et al. 2017). Another factor potentially driving weak connectivity in this species is small range size. When compared to more widely distributed species, Kirtland's Warblers are likely to have larger natal and adult dispersal distances relative to the size of their breeding and wintering ranges. Therefore, even with relatively high site fidelity, the small range size of Kirtland's Warblers may not provide enough geographic space to overcome the connectivity weakening effects of dispersal. Thus, we argue that the ephemeral nature of their habitat in combination with small range size likely favored the development of weak migratory connectivity in this species. The magnitude and frequency of dispersal remains unknown for most species, and no connectivity estimates exist for other range-restricted species. Therefore, it remains unclear whether these factors are likely to drive weak connectivity in other species as well. More research is clearly needed before we can fully understand how dispersal and range size interact to shape the strength of migratory connectivity.

\section{Comparison with other species}

Comparison of migratory connectivity among species is challenging given different sampling designs and analytical techniques. Moreover, the spatial resolution of many techniques used to describe connectivity in small songbirds is relatively coarse compared to the high resolution of our data (Bridge et al. 2011). At a range-wide scale, our results are perhaps most similar to that of the Bobolink (Dolichonyx oryzivorus). Renfrew et al. (2013) found that Bobolink populations located across the breeding range converge on a small wintering range in Bolivia. In contrast, two subspecies of Purple Martins (Progne subis subis and Progne subis arboricola) breeding across much of North America had stronger connectivity, wintering in two distant regions of Brazil (Fraser et al. 2012). The Purple Martin example highlights the importance of considering scale, because within the more restricted range of the eastern subspecies, individuals instead exhibited weak connectivity, with highly overlapping wintering areas (Fraser et al. 2012, 2017). Thus, at least in some species there appears to be a hierarchy of connectivity patterns; birds from spatially distant parts of the range may winter in different areas, but birds within more regional populations may largely overlap on the wintering grounds. Strong connectivity at the continental scale appears to be fairly common as evidenced by Yellow 
Warblers (Setophaga petechia; Boulet et al. 2006), American Redstarts (Setophaga ruticilla; Norris et al. 2006), Gray Catbirds (Dumetella carolinensis; Ryder et al. 2011), Wood Thrush (Hylocichla mustelina; Rushing et al. 2014, Stanley et al. 2015), Barn Swallows (Hirundo rustica; Hobson et al. 2015), and Blackthroated Blue Warblers (Setophaga caerulescens; Chamberlain et al. 1996, Rubenstein et al. 2002). In contrast to the eastern subspecies of Purple Martins, Swainson's Thrushes (Catharus ustulatus) and Ovenbirds (Seiurus aurocapilla) show moderate to strong connectivity even at finer regional scales (Cormier et al. 2013, Hallworth et al. 2015).

Many studies have only described migratory connectivity qualitatively. Among those studies that have quantified the strength of migratory connectivity, the Mantel test $\left(r_{M}\right)$ has been most commonly used. Compared to Kirtland's Warblers $\left(r_{M}=\right.$ -0.072 ; this study), Swainson's Thrushes $\left(r_{M}=0.72\right.$; Cormier et al. 2013), Ovenbirds $\left(r_{M}=0.213-0.635\right.$ depending on location, Hallworth et al. 2015; $r_{M}=0.83 \pm 0.05$, Cohen et al. 2017), and Wood Thrushes $\left(r_{M}=0.33\right.$; Stanley et al. 2015) all show stronger connectivity. The only study to use the MC metric to date found that Ovenbird connectivity, as estimated from geolocators (MC $=0.61 \pm 0.10$; Cohen et al. 2017), was stronger than in Kirtland's Warblers ( $\mathrm{MC}=0.012$; this study). The MC metric was in part designed to facilitate direct comparison of connectivity strength estimates among species (Cohen et al. 2017). Regardless of range size, a near-zero MC value or Mantel correlation is interpreted as no relationship between wintering and breeding distances between user-defined regions (MC) or individuals $\left(r_{M}\right)$. However, because of their small range size, Kirtland's Warblers may represent a special case in terms of both the causes and effects of weak connectivity. As discussed previously, small range size may favor weak connectivity. Furthermore, Kirtland's Warblers' small range size makes them likely to share more selective pressures throughout the annual cycle than would a continentally distributed species with similarly weak connectivity. Ultimately, it is difficult to frame Kirtland's Warbler connectivity in the context of other migratory species without estimates of the strength of connectivity from other range-restricted species.

\section{Conservation implications}

The weak connectivity found in Kirtland's Warblers indicates that the complete loss or disturbance of any one wintering site would have diffuse effects across the population, and vice versa (Dolman and Sutherland 1995, Sutherland 1996, Webster and Marra 2005). The apparent necessity of Kirtland's Warblers to locate widely dispersed and ephemeral habitat on both the breeding and wintering grounds may buffer populations of the species from localized habitat alterations, as has been suggested for Yellow Warblers (Boulet et al. 2006). This underscores the importance of landscape-level approaches to conservation of Kirtland's Warbler habitat on both the breeding and wintering grounds. Other species with similar connectivity patterns may also be resilient to loss of particular wintering sites (Webster and Marra 2005, McKinnon et al. 2013) and require landscape-scale conservation programs. Kirtland's Warblers may be resilient to the loss of wintering or breeding sites, but similar to other rangerestricted species, their small ranges make them more vulnerable to range-wide disturbances. For example, relative to the entire range of jack pine, a small-scale disease or invasive pest outbreak could threaten all occupied habitat in Michigan, impacting the vast majority of the population. It may therefore be desirable to further promote range expansion, as is being done in Wisconsin, Ontario, and the Upper Peninsula by more intensively managing habitat. On the wintering grounds, both sea-level rise (Nicholls and Cazenave 2010) and long-term drought (Neelin et al. 2006) are predicted throughout the Bahamian Archipelago. Sea-level rise alone is predicted to result in loss of between $11 \%$ and $60 \%$ of landmass in The Bahamas (Dasgupta et al. 2007, 2009). Rapid switching of wintering sites by a species is possible given even a small amount of underlying genetic variation in wintering location (Dolman and Sutherland 1995, Webster and Marra 2005). Genetic variation in Kirtland's Warbler wintering sites likely exists, as there are winter records outside the Bahamian Archipelago, including sight records from Hispaniola (Faanes and Haney 1989; W. J. Arendt, personal communication), Bermuda (Amos 2005), Cuba (Isada 2006, Cooper et al. 2017; S. Musgrave, personal communication), and south Florida (M. Kramer and E. Ardila, personal communication). Assuming that these extralimital winter records are indicative of genetic variation in wintering location and that the large landmasses of Cuba and Hispaniola provide some protection from the effects of climate change, particularly sea-level rise, then Cuba and Hispaniola might provide refuge to wintering Kirtland's Warblers in the future. Ultimately, by describing migratory connectivity between wintering and breeding sites, we have provided Kirtland's Warbler managers with new information on which to base research and conservation priorities.

Responses to this article can be read online at: http://www.ace-eco.org/issues/responses.php/1159

\section{Acknowledgments:}

We dedicate this paper in memory of the late Jim Stevens and Anthony White. Carol Bocetti, Eric Carey, Mike DeCapita, Peter Fasbender, Matthew Herbert, Todd Hogrefe, and Patrick Lederle played instrumental roles in obtaining permits needed to complete the work. Chris Mensing provided maps of Kirtland's Warbler locations, and Steve Sobaski created maps used by field observers. We thank the field observers who searched for banded Kirtland's Warblers: John Andersen, Rudy Badia, John Baumgartner, Patrick Doran, Ryan Dziedzic, George Falkenhagen, Michael Hamas, Robert Hess, Phil Huber, Scott Johnson, Everton Joseph, Samara Lawrentz, David Mehlman, Ray Perez, Mike Petrucha, Keith Philippe, John Probst, Montara Canon, Varada Shevade, Jim Stevens, Colin Studds, Mark Thomas, Paul Thompson, Jerry Weinrich, Dana Wloch, Andrew Zemke, and participants on the Kirtland's Warbler censuses from 2005 to 2007. We also thank Kim Grveles, Wisconsin Department of Natural Resources, and Joel Trick, U.S. Fish and Wildlife Service, for providing information on the Eleuthera-bandedmale Kirtland's Warblers found in Wisconsin; Steve Sjogren for providing information on Kirtland's Warblers located in the Upper Peninsula of Michigan; and Ken Tuininga and Tammy Richard for information on the Kirtland's Warbler found in Ontario. Trout Unlimited provided access to their property. A. Scarpignato and $R$. Hazen provided assistance in making Figure 1. We thank several anonymous reviewers for providing comments that improved the manuscript. 


\section{LITERATURE CITED}

Ambrosini, R., A. P. Møller, and N. Saino. 2009. A quantitative measure of migratory connectivity. Journal of Theoretical Biology 257:203-211. http://dx.doi.org/10.1016/j.jtbi.2008.11.019

Amos, E. J. R. 2005. First record of Kirtland's Warbler in Bermuda. Bermuda Audubon Society Newsletter 16:1.

Bächler, E., S. Hahn, M. Schaub, R. Arlettaz, L. Jenni, J. W. Fox, V. Afanasyev, and F. Liechti. 2010. Year-round tracking of small trans-Saharan migrants using light-level geolocators. PLoS ONE 5:e9566. http://dx.doi.org/10.1371/journal.pone.0009566

Bauer, S., S. Lisovski, and S. Hahn. 2016. Timing is crucial for consequences of migratory connectivity. OIKOS 125:605-612. http://dx.doi.org/10.1111/oik.02706

Bocetti, C. I., D. M. Donner, and H. F. Mayfield. 2014. Kirtland's Warbler (Setophaga kirtlandii). In P. G. Rodewald, editor. The birds of North America. Cornell Lab of Ornithology, Ithaca, New York, USA; American Ornithologists Union, Washington, D.C., USA. [online] URL: https://doi.org/10.2173/bna.19

Boulet, M., H. Gibbs, and K. A. Hobson. 2006. Integrated analysis of genetic, stable isotope, and banding data reveal migratory connectivity and flyways in the northern Yellow Warbler (Dendroica petechia: Aestiva group). Ornithological Monographs 61:29-78.

Boulet, M., and D. R. Norris. 2006. The past and present of migratory connectivity. Ornithological Monographs 61:1-13.

Bridge, E. S., J. F. Kelly, A. Contina, R. M. Gabrielson, R. B. MacCurdy, and D. W. Winkler. 2013. Advances in tracking small migratory birds: a technical review of light-level geolocation. Journal of Field Ornithology 84:121-137. http://dx.doi. org/10.1111/jofo.12011

Bridge, E. S., K. Thorup, M. S. Bowlin, P. B. Chilson, R. H. Diehl, R. W. Fléron, P. Hartl, R. Kays, J. F. Kelly, W. D. Robinson, and M. Wikelski. 2011. Technology on the move: recent and forthcoming innovations for tracking migratory birds. BioScience 61:689-698. http://dx.doi.org/10.1525/bio.2011.61.9.7

Chamberlain, C. P., J. D. Blum, R. T. Holmes, X. Feng, T. W. Sherry, and G. R. Graves. 1996. The use of isotope tracers for identifying populations of migratory birds. Oecologia 109:132-41. http://dx.doi.org/10.1007/s004420050067

Cohen, E. B., J. A. Hostetler, M. T. Hallworth, C. S. Rushing, T. S. Sillett, and P. P Marra. 2017. Quantifying the strength of migratory connectivity. Methods in Ecology and Evolution, in press. http://dx.doi.org/10.1111/2041-210X.12916

Cohen, E. B., J. A. Hostetler, J. A. Royle, and P. P. Marra. 2014. Estimating migratory connectivity of birds when re-encounter probabilities are heterogeneous. Ecology and Evolution 4:1659-1670. http://dx.doi.org/10.1002/ece3.1059

Cooper, N. W., M. T. Hallworth, and P. P. Marra. 2017. Lightlevel geolocation reveals wintering distribution, migration routes, and primary stopover locations of an endangered long-distance migratory songbird. Journal of Avian Biology 48:209-219. http:// dx.doi.org/10.1111/jav.01096
Cooper, N. W., T. W. Sherry, and P. P. Marra. 2015. Experimental reduction of winter food decreases body condition and delays migration in a long-distance migratory bird. Ecology 96:1933-1942. http://dx.doi.org/10.1890/14-1365.1

Cormier, R. L., D. L. Humple, T. Gardali, and N. E. Seavy. 2013. Light-level geolocators reveal strong migratory connectivity and within-winter movements for a coastal California Swainson's Thrush (Catharus ustulatus) population. Auk 130:283-290. http:// dx.doi.org/10.1525/auk.2013.12228

Dasgupta, S., B. Laplante, C. Meisner, D. Wheeler, and J. Yan. 2007. The impact of sea level rise on developing countries: a comparative analysis. Policy Research Working Paper No. 4136. The World Bank, Washington, D.C., USA.

Dasgupta, S., B. Laplante, C. Meisner, D. Wheeler, and J. Yan. 2009. The impact of sea level rise on developing countries: a comparative analysis. Climatic Change 93:379-388. http://dx.doi. org/10.1007/s10584-008-9499-5

Dolman, P. M., and W. J. Sutherland. 1995. The response of bird populations to habitat loss. Ibis 137:S38-S46. http://dx.doi. org/10.1111/j.1474-919X.1995.tb08456.X

Dray, S., and A. B. Dufour. 2007. The ade4 package: implementing the duality diagram for ecologists. Journal of Statistical Software 22:1-20. http://dx.doi.org/10.18637/jss.v022. i04

Ewert, D. N., K. R. Hall, J. M. Wunderle, Jr., D. Currie, S. M. Rockwell, S. B. Johnson, and J. D. White. 2012. Duration and rate of spring migration of Kirtland's Warblers. Wilson Journal of Ornithology 124:9-14. http://dx.doi.org/10.1676/11-073.1

Faanes, C. A., and J. C. Haney. 1989. First record of Kirtland's Warbler from the Dominican Republic and additional bird observations. Caribbean Journal of Science 25:30-35.

Fraser, K. C., A. Shave, A. Savage, A. Ritchie, K. Bell, J. Siegrist, J. D. Ray, K. Applegate, and M. Pearman. 2017. Determining fine-scale migratory connectivity and habitat selection for a migratory songbird using new GPS technology. Journal of Avian Biology 48:339-345. http://dx.doi.org/10.1111/jav.01091

Fraser, K. C., B. J. Stutchbury, C. Silverio, P. M. Kramer, J. Barrow, D. Newstead, N. Mickle, B. F. Cousens, J. C. Lee, D. M. Morrison, T. Shaheen, P. Mammenga, K. Applegate, and J. Tautin. 2012. Continent-wide tracking to determine migratory connectivity and tropical habitat associations of a declining aerial insectivore. Proceedings of the Royal Society B: Biological Sciences 279:4901-4906. http://dx.doi.org/10.1098/rspb.2012.2207

Gratto-Trevor, C., D. Amirault-Langlais, D. Catlin, F. Cuthbert, J. Fraser, S. Maddock, E. Roche, and F. Shaffer. 2012. Connectivity in Piping Plovers: do breeding populations have distinct winter distributions? Journal of Wildlife Management 76:348-355. http://dx.doi.org/10.1002/jwmg.261

Hallworth, M. T., T. S. Sillett, S. L.Van Wilgenburg, K. A. Hobson, and P. P. Marra. 2015. Migratory connectivity of a Neotropical migratory songbird revealed by archival light-level geolocators. Ecological Applications 25:336-347. http://dx.doi. org/10.1890/14-0195.1 
Harrison, X. A., J. D. Blount, R. Inger, D. R. Norris, and S. Bearhop. 2011. Carry-over effects as drivers of fitness differences in animals. Journal of Animal Ecology 80:4-18. http://dx.doi. org/10.1111/j.1365-2656.2010.01740.x

Heckscher, C. M., S. M. Taylor, J. W. Fox, and V. Afanasyev. 2011. Veery (Catharus fuscescens) wintering locations, migratory connectivity, and a revision of its winter range using geolocator technology. Auk 128:531-542. http://dx.doi.org/10.1525/auk.2011.10280

Hobson, K. A. 2005. Flying fingerprints: making connections with stable isotopes and trace elements. Pages 235-256 in R. Greenberg and P. P. Marra, editors. Birds of two worlds. John Hopkins University Press, Baltimore, Maryland, USA.

Hobson, K. A., and K. J. Kardynal. 2016. An isotope $\left(\delta^{34} S\right)$ filter and geolocator results constrain a dual feather isoscape $\left(\delta^{2} \mathrm{H}\right.$, $\delta^{13} \mathrm{C}$ ) to identify the wintering grounds of North American Barn Swallows. Auk 133:86-98. http://dx.doi.org/10.1642/AUK-15-149.1

Hobson, K. A., K. J. Kardynal, S. L. Van Wilgenburg, G. Albrecht, A. Salvadori, M. D. Cadman, F. Liechti, and J. W. Fox. 2015. A continent-wide migratory divide in North American breeding Barn Swallows (Hirundo rustica). PLOS ONE 10: e0129340. http://dx.doi.org/10.1371/journal.pone.0129340

Hostetler, J. A., M. T. Hallworth, C. S. Rushing, and E. B. Cohen. 2016. MigConnectivity: estimate strength of migratory connectivity for migratory animals. R package version 0.0.0.9007. [online] URL: https://github.com/SMBC-NZP/MigConnectivity

Isada, A. P. 2006. First sight record of Kirtland's Warbler (Dendroica kirtlandii) in Cuba. North American Birds 60:462-463.

Kellner, K. F., and R. K. Swihart. 2014. Accounting for imperfect detection in ecology: a quantitative review. PLOS ONE9:e111436. http://dx.doi.org/10.1371/journal.pone.0111436

Koronkiewicz, T. J., and M. K. Sogge. 2002. Southwestern Willow Flycatchers recaptured at wintering sites in Costa Rica. North American Bird Bander 26:161-162.

Koronkiewicz, T. J., M. K. Sogge, C. Van Riper III, and E. H. Paxton. 2006. Territoriality, site fidelity, and survivorship of Willow Flycatchers in Costa Rica. Condor 108:558-570. http://dx. doi.org/10.1650/0010-5422(2006)108[558:TSFASO]2.0.CO;2

Lisovski, S., C. M. Hewson, R. H. G. Klaasen, F. KornerNievergelt, M. W. Kristensen, and S. Hahn. 2012. Geolocation by light: accuracy and precision affected by environmental factors. Methods in Ecology and Evolution 3:603-612. http://dx. doi.org/10.1111/j.2041-210X.2012.00185.X

Marra, P. P., E. B. Cohen, S. R. Loss, J. E. Rutter, and C. M. Tonra. 2015. A call for full annual cycle research in animal ecology. Biology Letters 11:1-4. http://dx.doi.org/10.1098/rsbl.2015.0552

Marra, P. P., L. A. Culp, A. L. Scarpignato, and E. B. Cohen. 2014. Full annual cycle climate change vulnerability assessment for migratory birds of the Upper Midwest and Great Lakes region. Final report to the Upper Midwest and Great Lakes Landscape Conservation Cooperative. The Smithsonian Conservation Biology Institute, Migratory Bird Center, Washington, D.C., USA.
Marra, P. P., K. A., Hobson, and R. T. Holmes. 1998. Linking winter and summer events in a migratory bird by using stablecarbon isotopes. Science 282:1884-1886. http://dx.doi.org/10.1126/ science. 282.5395 .1884

McKinnon, E. A., K. C. Fraser, and B. J. M. Stutchbury. 2013. New discoveries in landbird migration using geolocators, and a flight plan for the future. Auk 130:211-222. http://dx.doi. org/10.1525/auk.2013.12226

Neelin, J. D., M. Münnich, H. Su, J. E. Meyerson, and C. E. Holloway. 2006. Tropical drying trends in global warming models and observations. Proceedings of the National Academy of Sciences of the United States of America 103:6110-6115. http:// dx.doi.org/10.1073/pnas.0601798103

Nicholls, R. J., and A. Cazenave. 2010. Sea-level rise and its impact on coastal zones. Science 328:1517-1520. http://dx.doi. org/10.1126/science. 1185782

Norris, D. R., P. P. Marra, G. J. Bowen, L. M. Ratcliffe, J. A. Royle, and T. K. Kyser. 2006. Migratory connectivity of a widely distributed songbird, the American Redstart (Setophaga ruticilla). Ornithological Monographs 61:14-28. http://dx.doi. org/10.2307/40166836

Probst, J. R. 1986. A review of factors limiting the Kirtland's Warbler on its breeding grounds. American Midland Naturalist 116:87-100. http://dx.doi.org/10.2307/2425940

Rappole, J. H., and A. R. Tipton. 1991. New harness design for attachment of radio transmitters to small passerines. Journal of Field Ornithology 62:335-337.

R Core Team. 2017. R: a language and environment for statistical computing. R Foundation for Statistical Computing, Vienna, Austria.

Renfrew, R. B., D. Kim, N. Perlut, J. Smith, J. Fox, and P. P. Marra. 2013. Phenological matching across hemispheres in a longdistance migratory bird. Diversity and Distributions 19:1008-1019. http://dx.doi.org/10.1111/ddi.12080

Richard, T. 2008. Confirmed occurrence and nesting of the Kirtland's Warbler at CFB Petawawa, Ontario: a first for Canada. Ontario Birds 26:2-15.

Richard, T. 2013. Seven years later: Kirtland's Warbler at Garrison Petawawa, 2006-2013. Ontario Birds 31:148-159.

Ricklefs, R. E., S. M. Fallon, S. C. Latta, B. L. Swanson, and E. Bermingham. 2005. Migrants and their parasites: a bridge between two worlds. Pages 210-221 in R. Greenberg and P. P. Marra, editors. Birds of two worlds. John Hopkins University Press, Baltimore, Maryland, USA.

Rimmer, C. C., and K. P. McFarland. 2001. Known breeding and wintering sites of Bicknell's Thrush. Wilson Bulletin 113:234-236. http://dx.doi.org/10.1676/0043-5643(2001)113[0234:KBAWSO]2.0. $\mathrm{CO} ; 2$

Rockwell, S. M., C. I. Bocetti, and P. P. Marra. 2012. Carry-over effects of winter climate on spring arrival date and reproductive success in an endangered migratory bird, Kirtland's Warbler (Setophaga kirtlandii). Auk 129:744-752. http://dx.doi.org/10.1525/ auk.2012.12003 
Rockwell, S. M., J. M. Wunderle, Jr., T. S. Sillett, C. I. Bocetti, D. N. Ewert, D. Currie, J. D. White, and P. P. Marra. 2017. Seasonal survival estimation for a long-distance migratory bird and the influence of winter precipitation. Oecologia 183:715-726. http:// dx.doi.org/10.1007/s00442-016-3788-x

Royle, J. A., and D. R. Rubenstein. 2004. The role of species abundance in determining breeding origins of migratory birds with stable isotopes. Ecological Applications 14:1780-1788. http:// dx.doi.org/10.1890/04-0175

Rubenstein, D. R., C. P. Chamberlain, R. T. Holmes, M. P. Ayres, J. R. Waldbauer, G. R. Graves, and N. C. Tuross. 2002. Linking breeding and wintering ranges of a migratory songbird using stable isotopes. Science 295:1062-1065. http://dx.doi.org/10.1126/ science. 1067124

Ruegg, K. C., E. C. Anderson, K. L. Paxton, V. Apkenas, S. Lao, R. B. Siegel, D. F. DeSante, F. Moore, and T. B. Smith. 2014. Mapping migration in a songbird using high-resolution genetic markers. Molecular Ecology 23:5726-5739. http://dx.doi. org/10.1111/mec.12977

Rushing, C. S., T. B. Ryder, and P. P. Marra. 2016a. Quantifying drivers of population dynamics for a migratory bird throughout the annual cycle. Proceedings of the Royal Society of London B: Biological Sciences 283:1-10. http://dx.doi.org/10.1098/rspb.2015.2846

Rushing, C. S., T. B. Ryder, J. F. Saracco, and P. P. Marra. 2014. Assessing migratory connectivity for a long-distance migratory bird using multiple intrinsic markers. Ecological Applications 24:445-456. http://dx.doi.org/10.1890/13-1091.1

Rushing, C. S., T. B. Ryder, A. Scarpignato, and J. F. Saracco. 2016b. Using demographic attributes from long-term monitoring data to delineate natural population structure. Journal of Applied Ecology 53:491-500. http://dx.doi.org/10.1111/1365-2664.12579

Ryder, T. B., J. W. Fox, and P. P. Marra. 2011. Estimating migratory connectivity of Gray Catbirds (Dumetella carolinensis) using geolocator and mark-recapture data. Auk 128:448-453. http://dx. doi.org/10.1525/auk.2011.11091

Sedinger, J. S., C. A. Nicolai, C. J. Lensink, C. Wentworth, and B. Conant. 2007. Black Brant harvest, density dependence, and survival: a record of population dynamics. Journal of Wildlife Management 71:496-506. http://dx.doi.org/10.2193/2005-768

Smith, T. B., S. Clegg, M. Kimura, and L. J. Lovette. 2005. Molecular genetic approaches to linking breeding and overwintering areas in five Neotropical migrant passerines. Pages 222-234 in R. Greenberg and P. P. Marra, editors. Birds of two worlds. John Hopkins University Press, Baltimore, Maryland, USA.

Stanley, C. Q., E. A. McKinnon, K. C. Fraser, M. P. MacPherson, G. Casbourn, L. Friesen, P. P. Marra, C. Studds, T. B. Ryder, N. E. Diggs, and B. J. M. Stutchbury. 2015. Connectivity of wood thrush breeding, wintering, and migration sites based on rangewide tracking. Conservation Biology 29:164-174. http://dx.doi. org/10.1111/cobi.12352

Stutchbury, B. J. M., S. A. Tarof, T. Done, E. Gow, P. M. Kramer, J. Tautin, J. W. Fox, and V. Afanasyev. 2009. Tracking long- distance songbird migration by using geolocators. Science 323:896. http://dx.doi.org/10.1126/science.1166664

Sutherland, W. J. 1996. Predicting the consequences of habitat loss for migratory populations. Proceedings of the Royal Society B: Biological Sciences 263:1325-1327. http://dx.doi.org/10.1098/ rspb.1996.0194

Sykes, Jr., P. W., and M. H. Clench. 1998. Winter habitat of Kirtland's Warbler: an endangered Nearctic/Neotropical migrant. Wilson Bulletin 110:244-261.

Taylor, P. D., T. L. Crewe, S. A. Mackenzie, D. Lepage, Y. Aubry, Z. Crysler, G. Finney, C. M. Francis, C. G. Guglielmo, D. J. Hamilton, R. L. Holberton, P. H. Loring, G. W. Mitchell, D. Norris, J. Paquet, R. A. Ronconi, J. Smetzer, P. A. Smith, L. J. Welch, and B. K. Woodworth. 2017. The Motus Wildlife Tracking System: a collaborative research network to enhance the understanding of wildlife movement. Avian Conservation and Ecology 12(1):8. http://dx.doi.org/10.5751/ACE-00953-120108

Taylor, C. M., and D. R. Norris. 2010. Population dynamics in migratory networks. Theoretical Ecology 3:65-73. http://dx.doi. org/10.1007/s12080-009-0054-4

Taylor, C. M., and B. J. M. Stutchbury. 2016. Effects of breeding versus winter habitat loss and fragmentation on the population dynamics of a migratory songbird. Ecological Applications 26:424-437. http://dx.doi.org/10.1890/14-1410

Thorup, K., F. Korner-Nievergelt, E. B. Cohen, and S. R. Baillie. 2014. Large-scale spatial analysis of ringing and re-encounter data to infer movement patterns: a review including methodological perspectives. Methods in Ecology and Evolution 5:1337-1350. http://dx.doi.org/10.1111/2041-210X.12258

Townsend, J. M., and C. M. Rimmer. 2006. Known natal and wintering sites of a Bicknell's Thrush. Journal of Field Ornithology 77:452-454. http://dx.doi.org/10.1111/j.1557-9263.2006.00077.x

Trick, J. A., K. Grveles, D. DiTommaso, and J. Robaidek. 2008. The first Wisconsin nesting record of Kirtland's Warbler (Dendroica kirtlandii). Passenger Pigeon 70:93-102.

Walkinshaw, L. H. 1983. Kirtland's Warbler: the natural history of an endangered species. Cranbrook Institute of Science, Bloomfield Hills, Michigan, USA.

Webster, M. S., and P. P. Marra. 2005. The importance of understanding migratory connectivity and seasonal interactions. Pages 199-209 in R. Greenberg and P. P. Marra, editors. Birds of two worlds. John Hopkins University Press, Baltimore, Maryland, USA.

Webster, M. S., P. P. Marra, S. M. Haig, S. Bensch, and R. T. Holmes. 2002. Links between worlds: unraveling migratory connectivity. Trends in Ecology and Evolution 17:76-83. http://dx. doi.org/10.1016/S0169-5347(01)02380-1

Wilcove, D. S., and M. Wikelski. 2008. Going, going, gone: is animal migration disappearing? PLoS Biol 6:e188. http://dx.doi. org/10.1371/journal.pbio.0060188

Wunderle, J. M., Jr., D. Currie, E. H. Helmer, D. N. Ewert, J. D. White, T. S. Ruzycki, B. Parresol, and C. Kwit. 2010. Kirtland's 
Warblers in anthropogenically disturbed early-successional habitats on Eleuthera, The Bahamas. Condor 112:123-127. http:// dx.doi.org/10.1525/cond.2010.090134

Wunderle, J. M., Jr., P. K. Lebow, J. D. White, D. Currie, and D. N. Ewert. 2014. Sex and age differences in site fidelity, food resource tracking, and body condition of wintering Kirtland's Warblers (Setophaga kirtlandii) in The Bahamas. Ornithological Monographs 80:1-62. http://dx.doi.org/10.1642/aoum.80-1 